\title{
man \\ Soil Water Content Directly Affects Bud Burst Rate in Single-Node Cuttings of Perennial Plants
}

\author{
Santiago Signorelli ${ }^{1,2, * \mathbb{D}}$, Juwita R. Dewi ${ }^{3}$ and Michael J. Considine ${ }^{2,4}$ \\ 1 Laboratorio de Bioquímica, Departamento de Biología Vegetal, Facultad de Agronomía, Universidad de la \\ República, Av. Garzón 780, Sayago CP, Montevideo 12900, Uruguay \\ 2 The Centre of Excellence in Plant Energy Biology, School of Molecular Sciences, The University of Western \\ Australia, 35 Stirling Highway, Crawley, WA 6009, Australia; michael.considine@uwa.edu.au \\ 3 School of Agriculture and Environment, The University of Western Australia, 35 Stirling Highway, \\ Crawley, WA 6009, Australia; juwita.dewi@research.uwa.edu.au \\ 4 Horticulture and Irrigated Agriculture, The Department of Primary Industries and Regional Development, \\ Perth, WA 6000, Australia \\ * Correspondence: ssignorelli@fagro.edu.uy; Tel.: +598-2354-0229
}

check for updates

Citation: Signorelli, S.; Dewi, J.R.; Considine, M.J. Soil Water Content Directly Affects Bud Burst Rate in Single-Node Cuttings of Perennial Plants. Agronomy 2022, 12, 360. https://doi.org/10.3390/ agronomy12020360

Academic Editor: Anita Ierna

Received: 16 December 2021

Accepted: 27 January 2022

Published: 31 January 2022

Publisher's Note: MDPI stays neutral with regard to jurisdictional claims in published maps and institutional affiliations.

Copyright: (C) 2022 by the authors. Licensee MDPI, Basel, Switzerland. This article is an open access article distributed under the terms and conditions of the Creative Commons Attribution (CC BY) license (https:// creativecommons.org/licenses/by/ $4.0 /)$.

\begin{abstract}
The use of single-node cuttings of shoots as explants to study bud dormancy and its physiology under controlled conditions is a common practice in grapevine (Vitis vinifera L.) or other perennial plant research. In particular, this method has been extensively used to understand the effect of different chemicals on bud dormancy and bud burst. However, the soil water content in those experiments is usually not reported and its relevance is often neglected. Here, we observed that an unevenly distributed soil water content in a tray containing multiple explants results in an uneven pattern of bud burst within the same treatment. Thus, we hypothesised that soil water content can dramatically affect bud burst. To investigate this, we first established that fresh single-node cuttings were able to transport water into the buds. We then tested the rate of bud burst at different water treatments (35\%, 55\%, 70\%, 85\%, and 100\% of field capacity; FC). We observed a clear dependence of bud burst on water, in which, at very low levels of water, bud burst does not occur; after 35\% FC, bud burst rate increases with water content until around 85\% FC; and, from 85\% FC, bud burst rate becomes independent of water content. These data highlight the critical importance of monitoring soil water content in any bud burst assay in perennials. Finally, we provide a detailed protocol for determining and controlling field capacity and other soil water content indicators.
\end{abstract}

Keywords: bud; bud burst; development; dormancy; explants; field capacity; gravimetric water content; grapevine; perennial plants; water

\section{Introduction}

The use of explants of perennial plants is a common practice to evaluate kinetics of bud burst, for instance, to evaluate the depth of dormancy, the effect of environmental clues, or applied chemicals on bud burst [1-4]. The use of explants enables the use of controlled conditions, which is a major limitation when working with perennial plants, as well as removing the influence of dominance influences of the corpus and competing sinks. Despite the wide use of this methodology, the influence of water availability on bud burst has not been reported. This is particularly important because the application of chemicals usually implies adding water to the single-node cuttings, as water is the most common solvent used. In addition, the water content of soil in single-node cuttings experiments is commonly not reported. We hypothesise that soil water content can explain much of the stochastic variability observed in bud burst experiments and, thus, that determining a fixed water content within the experiments is critical to underpin the validity and reproducibility of data reported. 
Water content in the soil is usually expressed as volumetric water content (VWC), gravimetric water content (GWC), or a percentage of field capacity (FC), which simply refers to the maximum amount of water that a soil can retain. VWC $\left(\Theta_{\mathrm{v}}\right)$ is calculated as:

$$
\Theta_{\mathrm{v}}=\left(\mathrm{V}_{\mathrm{wet}}-\mathrm{V}_{\mathrm{dry}}\right) / \mathrm{V}_{\mathrm{dry}}
$$

$\mathrm{V}_{\text {wet }}$ being the volume of wet soil and $\mathrm{V}_{\text {dry }}$ the volume of dry soil. GWC $\left(\Theta_{\mathrm{g}}\right)$ is calculated as:

$$
\Theta_{\mathrm{g}}=\left(\mathrm{W}_{\text {wet }}-\mathrm{W}_{\text {dry }}\right) / \mathrm{W}_{\text {dry }}
$$

$W_{\text {wet }}$ being the weight (mass) of wet soil and $W_{\text {dry }}$ the weight of dry soil. Given that measuring mass is simpler than volume, GWC is generally preferred over VWC.

The objectives of this work were to evaluate the effect of soil water content on bud burst of grapevine single-node cuttings and to provide a protocol to eliminate water content as a variable in single-node cutting experiments. For this purpose, we determined whether uneven water content affects bud burst, whether dormant buds are able to take up water, and the kinetics of bud burst at different $\%$ of FC.

\section{Materials and Methods}

\subsection{Preparation of Pots and Calculation of Field Capacity}

The substrate of potting mix at $\mathrm{pH}$ \%.0, containing fine composted pine bark, coco peat, and brown river sand in the ratio of 2.5:1:1.5 $(w / w)$, was homogenously mixed and distributed among 19 seedling trays on trays, each adjusted to a mass of $2500 \mathrm{~g}$ (Figure 3A). As the potting mix was not completely dry, three additional samples of around $30 \mathrm{~g}$ were used to determine the initial moisture content and, hence, initial dry weight. The $30 \mathrm{~g}$ samples were incubated in an oven at $105{ }^{\circ} \mathrm{C}$ for two days to determine the dry weight (Figure 3B). Once the moisture was determined in the subsamples, the dry weight of the soil in each tray was calculated (Figure 3C). Out of the 19 trays, 15 were used for planting three replicates of the five treatments described below. The remaining four trays were used to determine FC. The FC trays were saturated with water and left in the washing area where they were able to drain (Figure 3D). After $3 \mathrm{~h}$, the trays were placed on a stand with paper below to monitor more accurately the presence of dripping from the trays. Replacing the paper once wet and inspecting every $30 \mathrm{~min}$, we determined the weight of the pots at field capacity when no more drops came out from the tray for $1 \mathrm{~h}$ (Figure 3E,F). Once 100\% FC was established, the weight to achieve the different FC was calculated (Figure 3G).

\subsection{Plant Material and Growth Conditions}

Grapevine (Vitis vinifera L.) cv. Merlot canes containing mature, dormant buds from node 3 to 10 were collected from a commercial vineyard in Margaret River, Australia $\left(34^{\circ} \mathrm{S}\right.$, $115^{\circ} \mathrm{E}$ ) on the second week of June 2017 (winter in the south hemisphere). At that time, the local photoperiod was 10/14 h light/dark (sunrise 07:23 am, sunset 5:17 pm). On the collection day, the temperature was $18{ }^{\circ} \mathrm{C} / 10{ }^{\circ} \mathrm{C}$ (high/low), the average temperature for the month was $13{ }^{\circ} \mathrm{C}$, and the highest and lowest in that month were $23{ }^{\circ} \mathrm{C}$ (11 June) and $3{ }^{\circ} \mathrm{C}$ (9 June), respectively. The highest humidity was $96 \%$ ( 1 June) and $25 \%$ (9 June). The canes were wrapped on newspaper, externally moistened by spraying water, placed on black bags sealed with tape to be transported to the lab, and stored at $4{ }^{\circ} \mathrm{C}$ for 10 days. Single-node cuttings (explants) were cut about $4-5 \mathrm{~cm}$ below the node until $2-3 \mathrm{~cm}$ above the node, and immediately planted on the trays containing the potting mix described above. A total of 90 single-node cuttings were planted per treatment divided in three different trays (replicates). Before planting, water was added to each tray until reaching the exact weight for its corresponding treatment of field capacity \%. Once the explants were planted, the new weight for each tray was recorded to know the new weight for the treatment tray considering the weight of the plant material. Explants were grown at $20{ }^{\circ} \mathrm{C}$ under a photoperiod of 12:12 h, illuminated with a photosynthetic photon flux density of $100 \mu \mathrm{mol} \cdot \mathrm{m}^{-2} \cdot \mathrm{s}^{-1}$, for 49 days. Explants were watered every day on a set of scales until 
reaching the corresponding weight of the tray, including the initial weight of the plant material, for each particular water treatment (Figure $3 \mathrm{H}$ ).

\subsection{Water Treatments}

To assess the effect of soil water availability on bud burst, we defined five water treatments corresponding to $35 \%, 55 \%, 70 \%, 85 \%$, and $100 \%$ of FC. Values below $35 \%$ of FC were not considered, as it is unlikely to have growth in such conditions when using an explant system (absence of roots).

\subsection{Micro-Computed Tomographies}

To investigate the buds' water uptake capacity, buds were dissected from the cane and incubated overnight with caesium iodide (CsI) $10 \%$ at $4{ }^{\circ} \mathrm{C}$ or without CsI (control). $3 \mathrm{D}$ imaging using $\mu \mathrm{CT}$ was performed on each bud (BBCH scale: 00-01 [5]). The microcomputed tomographies $(\mu \mathrm{CT})$ were performed with a nanofocus CT system (Phoenix Nanotom, General Electric, Heidelberg, Germany) after incubation. Buds were mounted on a rotation stage by means of a Parafilm wrap. A total of 2400 projection images per scan were taken with $0.15^{\circ}$ angular steps for a full $360^{\circ}$ rotation. Capture time for each image was $500 \mathrm{~ms}$. Settings were $55 \mathrm{kV} / 182 \mu \mathrm{A}$ for control samples and $60 \mathrm{kV} / 167 \mu \mathrm{A}$ for CsI samples. Image pixel resolution was 2.50-3.25 $\mu \mathrm{m}$. Slice reconstruction was performed by Octopus Reconstruction version 8.9.0.9 (XRE, Ghent, Belgium) using the filtered back-projection method.

\section{Results}

To determine if uneven distribution of water affects bud burst, we placed single-node cuttings on seedling trays on concave plastic trays, in which the water was preferably distributed towards the centre of the seedling trays (Figure 1). After 35 days, we observed that the bud burst was not spatially uniform, whereby bud burst of explants in the centre of the tray (dashed rectangle in Figure 1A) greatly exceeded those in the periphery (Figure 1). This was consistent with the hypothesis that water availability was an important variable affecting bud burst kinetics in single-node cutting experiments.

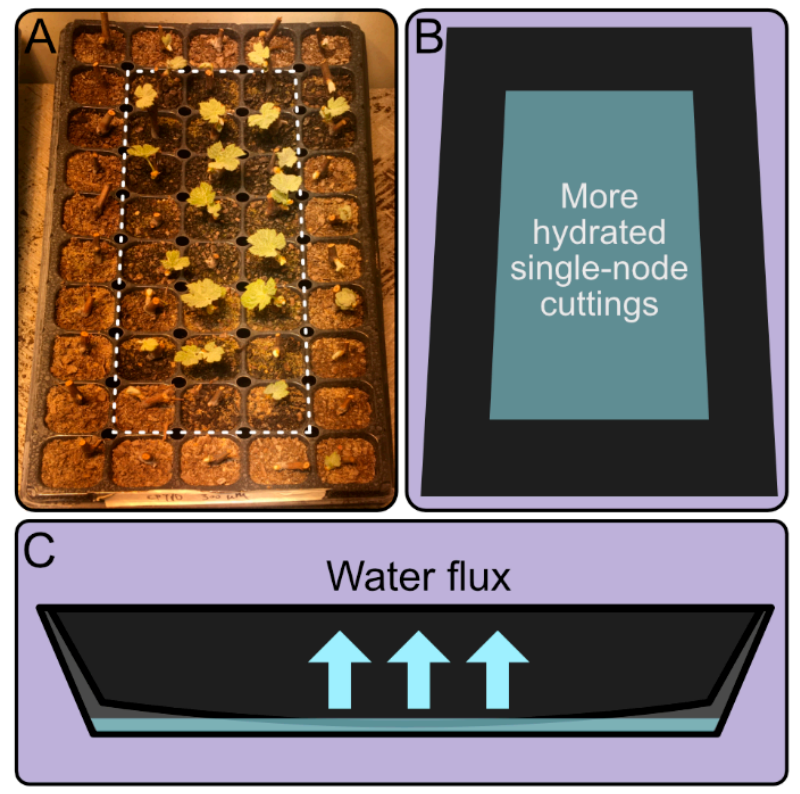

Figure 1. Irregular bud burst on a seedling tray with uneven distribution of water. (A) Representative picture of single-node cuttings after 35 days when water was not homogenously distributed across the tray. (B) Top view representation of the most hydrated area of the tray. (C) Lateral view representation of the tray showing the bending of the seedling tray and the water flux generated towards the centre. 
It is well documented that quiescent buds are isolated to prevent dehydration during winter, particularly through the restriction of aquaporin activity, plasmodesmata conductance, and apoplastic conductivity [6-10]. For water to have a direct effect on bud burst, it needs to be transported to the bud after transferring the single-node cutting to the seedling tray. Therefore, we tested if quiescent buds were able to transport water immediately after dissecting them from the cane. Using a contrast agent, and analysing $\mu \mathrm{CT}$ data, we observed that water was effectively transported through the bud $24 \mathrm{~h}$ after incubation (Figure 2).
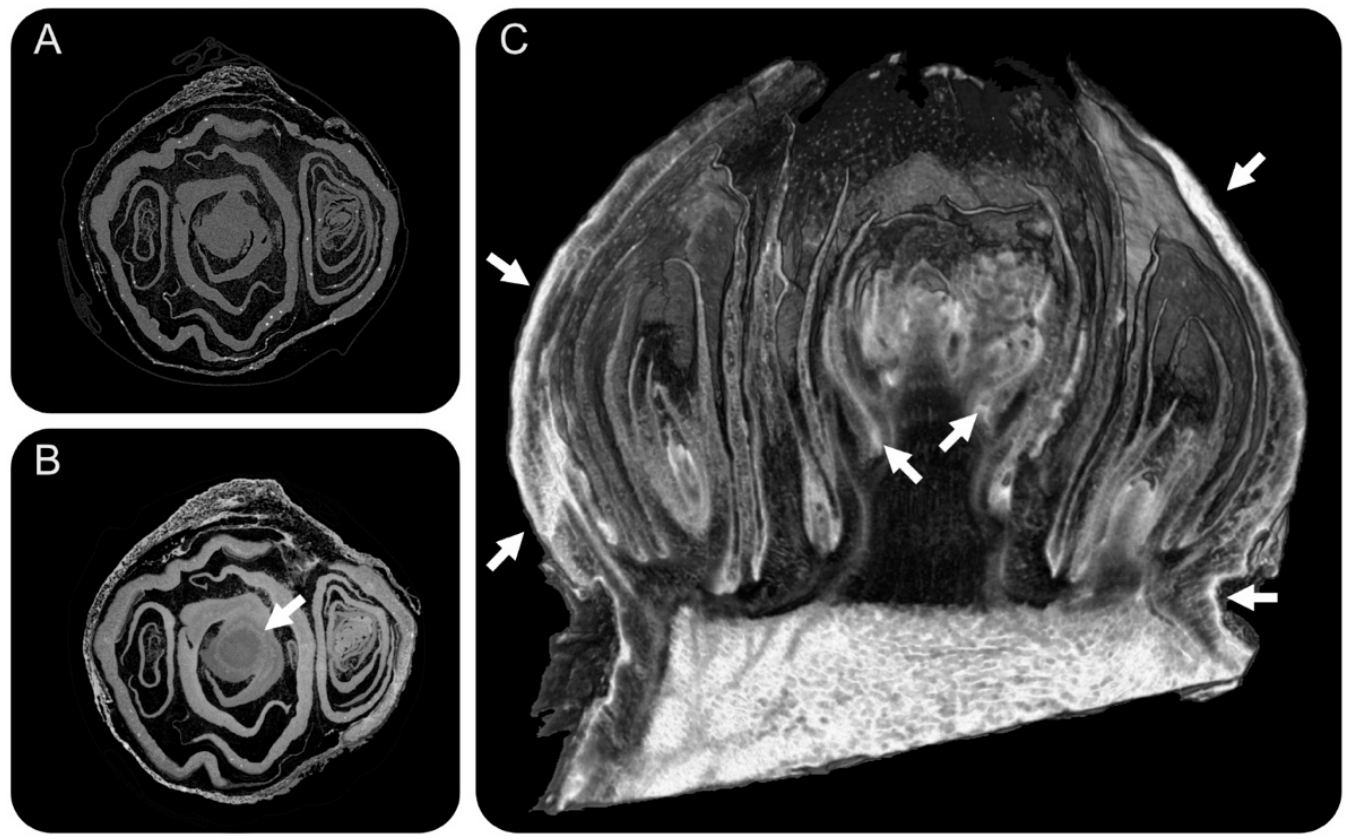

Figure 2. Micro-computed tomographies $(\mu \mathrm{CT})$ of buds $24 \mathrm{~h}$ after being dissected from the cane and incubated with or without contrast agents (CsI). (A) Top view section of a control bud without contrast agent. (B) Top view section of a bud incubated with the contrast agent. (C) Lateral view of a bud incubated with the contrast agent. The arrows indicate the contrast agent, which is observed as white colour. $n=3$.

Given the evidence presented by Figures 1 and 2, we set up an experiment controlling the water content of the pots every day (Figure 3) for 47 days to see if different kinetics of bud burst are observed. Figure 3 explains all the steps required to control the water content in soil. In our case, we chose $35 \%, 55 \%, 70 \%, 85 \%$, and $100 \%$ of FC to test if there is a correlation between bud burst and soil water content.

We observed a strong correlation between bud burst and water treatments (Figure 4). Explants grown on $100 \%$ and $85 \%$ FC had the greatest rate of bud burst, reaching $50 \%$ bud burst at about $24 \mathrm{~d}$, followed by those at 70\% FC, which reached $50 \%$ bud burst at $30 \mathrm{~d}$. Bud burst of explants grown on 55\% FC was considerably delayed, reaching $50 \%$ bud burst at $44 \mathrm{~d}$, revealing how small variations in water content can make important differences in bud burst rates. Finally, explants grown on 35\% FC did not reach $50 \%$ bud burst within the time evaluated (Figure $4 \mathrm{~A}$ ); only $8 \%$ of the buds had burst at the end of the experiment. The curves for $100 \%$ and $85 \%$ FC were almost indistinguishable, being only significantly different between day 25 and 33 (Figure 4A), where the curve for 100\% FC reached higher values. Conversely, clear and significant differences were observed between all the other curves since the start of bud burst for each curve. Overall, the graph of Figure 4A suggests a triphasic behaviour between bud burst rate and water content of soil, in which, at very low levels of water (e.g., $<35 \%$ FC), there is no correlation, as buds are not going to burst (i.e., a zero order kinetic for water), a second phase (e.g., 35-85\% FC), in which there is a positive correlation between bud burst rate and water content, and a third phase (e.g., 
$>85 \%$ FC), in which bud burst rate became, again, independent of water content (i.e., a zero-order kinetic for water), most likely because water was no longer a limiting factor and bud burst is determined by other factors.

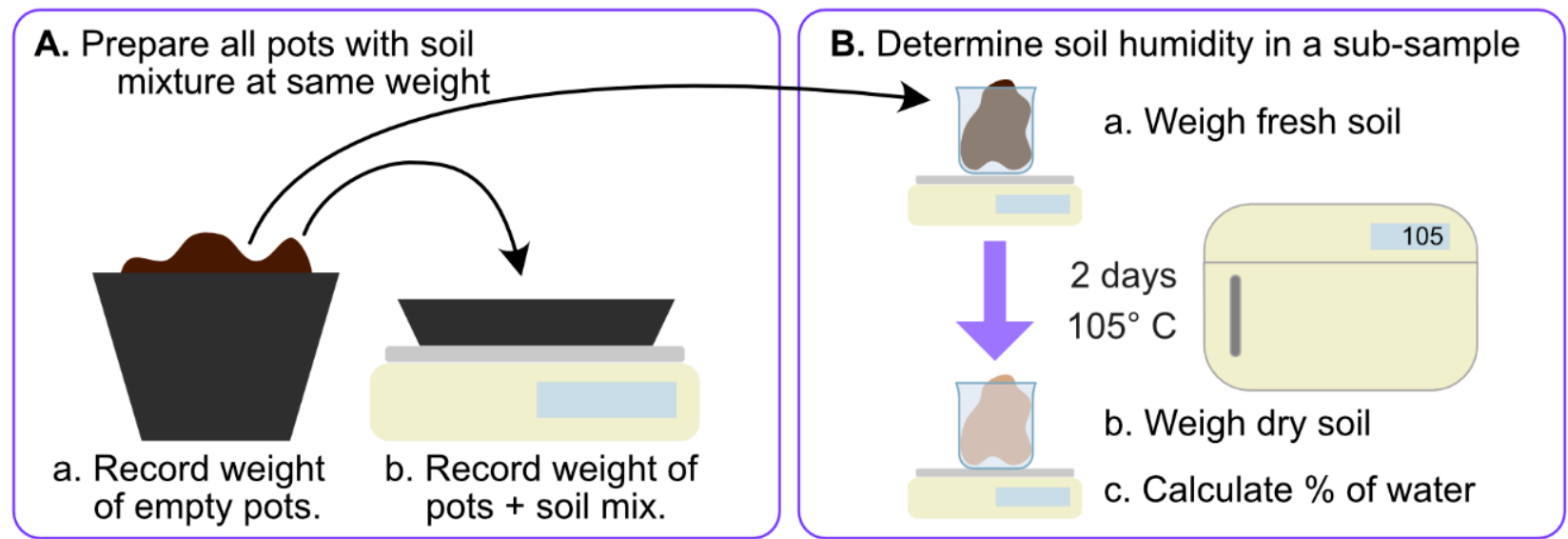

C. Determine weight of dry soil in pots

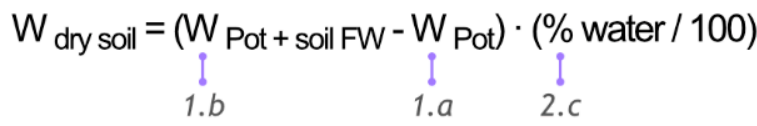

Note: this is your 0 in terms of GWC

F. Determine weight of soil in pots at $100 \%$ FC

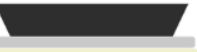

a. Record weight of pots at $100 \%$ FC.

b. Calculate weight of soil at $100 \% \mathrm{FC}$ as:

$W_{\text {soil at } 100 \% \mathrm{FC}}=\mathrm{W}_{\text {Pot }+ \text { soil at } 100 \% \mathrm{FC}}-\mathrm{W}_{\text {Pot }}$

Note: If GWC is preferred, you can calculate your GWC at $100 \%$ FC.

H. During your experiment, irrigate the pots on a scale, so you can control the water you add until reaching the desired weight for each \% FC or GWC

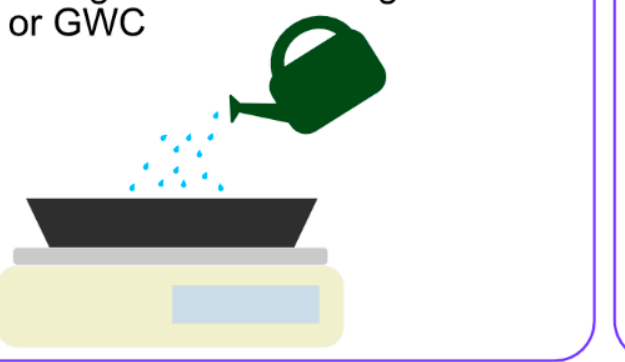

D. Irrigate to field capacity until saturation

E. Allow to drain until no drop is observed for $1 \mathrm{~h}$

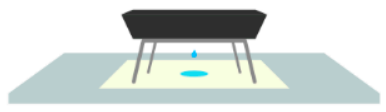

G. Determine the weight of the pot at each \% of FC (or GWC) desired.

This can be done by rule of three:

For example, if the total weight at $100 \%$ FC is $1 \mathrm{~kg}$ and the weight of the pot and dry soil is $300 \mathrm{~g}$, the pot has $700 \mathrm{~g}$ of water at $100 \%$ FC. Therefore, at $50 \%$ FC it should have $350 \mathrm{~g}$ of water and the total weight of the pot and soil at 50\% FC should be $650 \mathrm{~g}$.

or by plotting $\mathrm{W}_{\text {Pot + soil }}$ Vs \%FC (or GWC):

Plot your data and calculate the value of the slope (a):

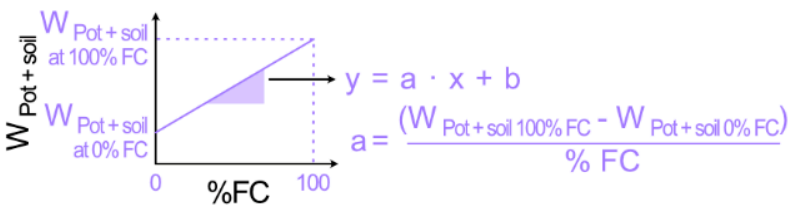

With the value of the slope (a), you can determine the weight of the pot for any desired \% FC as follows:

$$
\mathrm{W}_{\text {Pot }+ \text { soil }}=\mathrm{a} \cdot \% \mathrm{FC}+\mathrm{W}_{\text {Pot }+ \text { soli } 0 \% \mathrm{FC}}
$$

Figure 3. Procedure to determine and control the field capacity in soil and the control of in-soil water levels during the experiment. (A-H) describe the successive steps of this protocol, being (A) step 1 and $(\mathbf{H})$ step 8 . The values shown in panel $(\mathbf{G})$ are only for exemplification, and are not real data. 
A

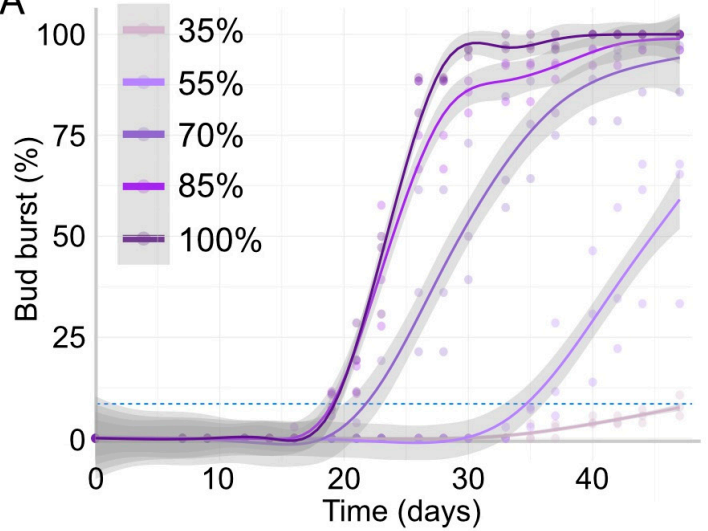

B

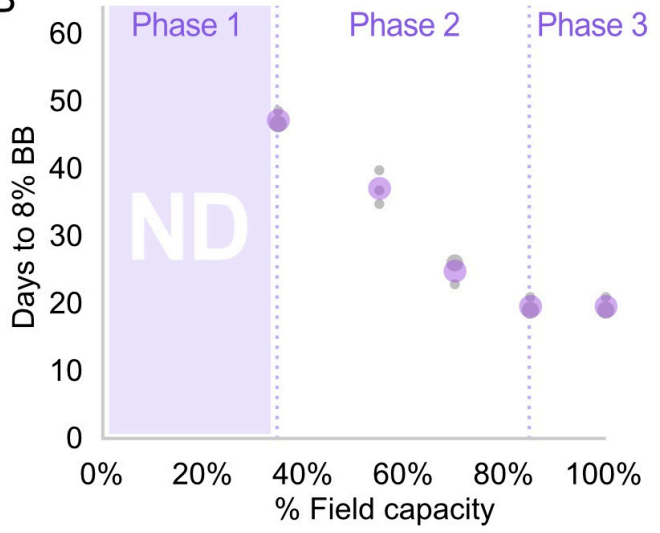

Figure 4. Kinetics of bud burst at different water contents in soil expressed as \% of FC. (A) Bud burst percentages for each water treatment. The curve represents a regression determined with the generalised additive model, with its $95 \%$ confidence level intervals for the prediction presented as the surrounding grey area. The dashed light-blue line marks the $8 \%$ bud burst threshold used to determine the days plotted in B. (B) Three kinetic behaviours of bud burst rate in relation to water content. The purple circles indicate the means and the grey circles indicate the independent replicates; the bigger the circle, the more replicates giving the same result $(n=3)$. The first phase indicates a range of water content in which bud burst was unlikely to happen due to water restrictions, where no data (ND) was collected.

To explore this triphasic behaviour further and investigate whether the positive correlation observed is linear, we plotted the days to reach $8 \%$ bud burst in relation to the $\%$ of FC (Figure 4B). In this case, the three kinetic phases are clearly identified and a linear correlation was observed for the second phase (Figure 4B), suggesting that the kinetic is of the first order (i.e., bud burst rate increases linearly with water content). After 85\% FC, the time to reach $8 \%$ bud burst is the same as at $100 \%$, confirming that the initiation of bud burst was not affected by water contents of soil above $85 \%$ of FC. It is important to note, however, that, if values as high as $90 \%$ bud burst are used, there may be an effect of water, as we observed that the buds at $100 \%$ of FC were the first to reach the plateau of nearly 100\% bud burst (Figure 4A).

\section{Discussion}

This study aimed to test the often overlooked importance of water availability on bud burst kinetics in explant studies, which have become the main morphometric test for the depth of dormancy in perennating buds. The buds used in this study were collected towards the end of winter, and further stored at $4{ }^{\circ} \mathrm{C}$ prior to experimentation, in order to eliminate dormancy as a factor. Our results demonstrated that quiescent buds of explants can transport water as soon as they are subjected to water treatments (Figure 2) and that water availability can directly and strongly influence the rate of bud burst when provided within the range of 35 to $85 \%$ FC (Figure 4 ). For instance, a reduction of $15 \%$ FC can delay bud burst by $\sim 50 \%$ time (i.e., from 30 days to 44 days to reach $50 \% \mathrm{BB}$ ). This demonstrates that a tight control of water content in soil is required when determining bud burst rate kinetics for comparing different treatments, as these differences observed by water can be much greater (i.e., 10 days) than those sometimes observed by different exogenous treatments of molecules (e.g., 2-4 days). Therefore, we provided here an illustrative and detailed protocol (Figure 3) explaining how to determine the different percentages of FC when setting up the experiment and how to follow up the experiment. As FC here is expressed as \% of mass of water by mass of substrate, a set of scales is required for these calculations. However, it is also possible to use volumetric units and express as volume of water per volume of substrate. We understand that the determination of volume is usually more complex in most laboratories. In our work, we presented all the data as \% 
FC; however, it is also possible to express the data as GWC or VWC using the equations described in introduction. Alternatively, if the number of treatments represent a major constraint to control daily the water levels of the experiment, we suggest working always above $80-85 \%$ FC, a range in which, in our experimental conditions, bud burst takes place and becomes independent of water levels. Thus, we define this as a "safety zone" of water contents when comparing bud burst rates under different treatments, particularly important when the treatments of chemicals implicate the use of water. However, this "safety zone" should be ideally determined in each lab depending on the substrate used, because different substrates have a different water retention capacity, resulting in significant differences in water content relative to soil (i.e., GWC or VWC). In terms of GWC, 85\% of FC in our system represented $0.94 \mathrm{~g}_{\text {water }} \cdot \mathrm{g}_{\text {soil }}{ }^{-1}$ and $100 \%$ of FC was $1.11 \mathrm{~g}_{\text {water }} \cdot \mathrm{g}_{\text {soil }}{ }^{-1}$.

Several earlier studies have illustrated the regulated changes in free and bound water [10], in the activity of aquaporin transporters [6,11], the role of plasmodesmata in dormancy transitions of perennating buds [7], the expansion of apoplastic connectivity upon bud burst [9], and the change dynamics in moisture content in the bud across the season [11]. The fact that water has a strong effect on bud burst in explant further supports the importance of those biological processes controlling water content in the bud, such as plasmodesmata regulation, aquaporins activity, etc. A deeper understanding of the signals controlling these mechanisms could allow scientists to develop managing practices to manipulate bud burst that can be used by farmers to synchronize bud burst better. Besides the biochemical mechanism regulating water transport, environmental clues can also affect water availability and transport to the bud. In grapevine, shade [12] and water deficit [13] were shown to reduce water transport capacity in field conditions, whereas high temperatures increase it [14]. The xylem network varies between grapevine cultivars; therefore, some cultivars have greater hydraulic conductivity than others (e.g., Thompson Seedless (high) vs. Merlot (low)) $[15,16]$, as well as the xylem hydraulic response to environmental clues [15]. Likewise, in other perennials, several studies showed that frosting or cold temperatures affect water uptake and transport through the vascular system $[17,18]$. Therefore, it is expected that environmental clues modulate bud water content in perennials grown in the field. This aspect has not been less explored in research where xylem conductivity was investigated. However, a study conducted on apple trees, where soil frost was prolonged by soil insulation, has shown that the prolonged frost not only reduced water conductivity, but also buds' water content, and this correlated with a delayed bud burst [17]. Hence, the conclusion of our study about the effect of water content on bud burst using an explant system is likely to be translatable to what occurs in field conditions.

\section{Conclusions}

Single-node cuttings containing quiescent buds are able to transport water, and water has a strong effect on the rate of bud burst. Therefore, we conclude that statements of water content must be included in experiments on bud burst in explants. Soil water content must be controlled in these experiments to avoid the variation in water contents that confounds the differences caused by the specific treatment by chemicals or environmental conditions in bud burst rates, and to avoid false positive effects.

Author Contributions: Conceptualisation, S.S.; methodology, S.S. and M.J.C.; formal analysis, S.S.; investigation, S.S. and J.R.D.; resources, M.J.C.; writing—original draft preparation, S.S.; writingreview and editing, S.S. and M.J.C.; funding acquisition, M.J.C. All authors have read and agreed to the published version of the manuscript.

Funding: This research was funded by the Australian Research Council Discovery Project DP150103211.

Acknowledgments: We thank Jeremy Shaw, Pieter Verboven, and Zi Wang, who contributed to the generation of microCT data. SS is a grateful member of the Uruguayan system of researchers (Sistema Nacional de Investigadores, SNI, Uruguay).

Conflicts of Interest: The authors declare no conflict of interest. 


\section{References}

1. Vergara, R.; Parada, F.; Rubio, S.; Pérez, F.J. Hypoxia induces $\mathrm{H}_{2} \mathrm{O}_{2}$ production and activates antioxidant defence system in grapevine buds through mediation of $\mathrm{H}_{2} \mathrm{O}_{2}$ and ethylene. J. Exp. Bot. 2012, 63, 4123-4131. [CrossRef] [PubMed]

2. Meitha, K.; Agudelo-Romero, P.; Signorelli, S.; Gibbs, D.J.; Considine, J.A.; Foyer, C.H.; Considine, M.J. Developmental control of hypoxia during bud burst in grapevine. Plant Cell Environ. 2018, 41, 1154-1170. [CrossRef] [PubMed]

3. Antolín, M.C.; Santesteban, H.; Ayari, M.; Aguirreolea, J.; Sánchez-Díaz, M. Grapevine Fruiting Cuttings: An Experimental System to Study Grapevine Physiology under Water Deficit Conditions. In Methodologies and Results in Grapevine Research; Springer: Dordrecht, The Netherlands, 2010; pp. 151-163. [CrossRef]

4. Mullins, M.G.; Bouquet, A.; Williams, L.E. Biology of the grapevine. In The Biology of Horticultural Crops; Cambridge University Press: Cambridge, UK, 1992; p. 239. ISBN 9780521305075.

5. Coombe, B.G. Growth Stages of the Grapevine: Adoption of a system for identifying grapevine growth stages. Aust. J. Grape Wine Res. 1995, 1, 104-110. [CrossRef]

6. Yooyongwech, S.; Horigane, A.K.; Yoshida, M.; Yamaguchi, M.; Sekozawa, Y.; Sugaya, S.; Gemma, H. Changes in aquaporin gene expression and magnetic resonance imaging of water status in peach tree flower buds during dormancy. Physiol. Plant. 2008, 134, 522-533. [CrossRef] [PubMed]

7. Rinne, P.L.H.; Kaikuranta, P.M.; Van Schoot, C. Der The shoot apical meristem restores its symplasmic organization during chilling-induced release from dormancy. Plant J. 2001, 26, 249-264. [CrossRef] [PubMed]

8. Beauvieux, R.; Wenden, B.; Dirlewanger, E. Bud dormancy in perennial fruit tree species: A pivotal role for oxidative cues. Front. Plant Sci. 2018, 9, 657. [CrossRef] [PubMed]

9. Signorelli, S.; Shaw, J.; Hermawaty, D.; Wang, Z.; Verboven, P.; Considine, J.A.; Considine, M.J. The initiation of bud burst in grapevine features dynamic regulation of the apoplastic pore size. J. Exp. Bot. 2020, 71, 719-729. [CrossRef] [PubMed]

10. Yooyongwech, S.; Horigane, A.K.; Yoshida, M.; Sekozawa, Y.; Sugaya, S.; Cha-Um, S.; Gemma, H. Hydrogen cyanamide enhances MRI-measured water status in flower buds of peach (Prunus persica L.) during winter. Plant Omics 2012, 5, 400-404.

11. Velappan, Y.; Chabikwa, T.G.; Considine, J.A.; Agudelo-Romero, P.; Foyer, C.H.; Signorelli, S.; Considine, M.J. The bud dormancy disconnect: Latent buds of grapevine are dormant during summer despite a high metabolic rate. J. Exp. Bot. 2022. [CrossRef] [PubMed]

12. Schultz, H.R.; Matthews, M.A. Xylem development and hydraulic conductance in sun and shade shoots of grapevine (Vitis vinifera L.): Evidence that low light uncouples water transport capacity from leaf area. Planta 1993, 190, 393-406. [CrossRef]

13. Lovisolo, C.; Schubert, A. Effects of water stress on vessel size and xylem hydraulic conductivity in Vitis vinifera L. J. Exp. Bot. 1998, 49, 693-700. [CrossRef]

14. Galat Giorgi, E.; Keller, M.; Sadras, V.; Roig, F.A.; Perez Peña, J. High temperature during the budswell phase of grapevines increases shoot water transport capacity. Agric. For. Meteorol. 2020, 295, 108173. [CrossRef]

15. Pouzoulet, J.; Pivovaroff, A.L.; Scudiero, E.; de Guzman, M.E.; Rolshausen, P.E.; Santiago, L.S. Contrasting adaptation of xylem to dehydration in two Vitis vinifera L. sub-species. Vitis-J. Grapevine Res. 2020, 59, 53-61. [CrossRef]

16. Brodersen, C.R.; Choat, B.; Chatelet, D.S.; Shackel, K.A.; Matthews, M.A.; McElrone, A.J. Xylem vessel relays contribute to radial connectivity in grapevine stems (Vitis vinifera and V. Arizonica; Vitaceae). Am. J. Bot. 2013, 100, 314-321. [CrossRef] [PubMed]

17. Beikircher, B.; Mittmann, C.; Mayr, S. Prolonged soil frost affects hydraulics and phenology of apple trees. Front. Plant Sci. 2016, 7, 867. [CrossRef] [PubMed]

18. Christensen-Dalsgaard, K.K.; Tyree, M.T. Frost fatigue and spring recovery of xylem vessels in three diffuse-porous trees in situ. Plant Cell Environ. 2014, 37, 1074-1085. [CrossRef] [PubMed] 